\title{
Bringing optics to Fab Labs in Europe
}

Aurèle Adam, Thim Zuidwijk, Paul Urbach

Aurèle Adam, Thim Zuidwijk, Paul Urbach, "Bringing optics to Fab Labs in Europe," Proc. SPIE 10452, 14th Conference on Education and Training in Optics and Photonics: ETOP 2017, 104523M (16 August 2017); doi: 10.1117/12.2281969

SPIE Event: 14th Conference on Education and Training in Optics and Photonics, ETOP 2017, 2017, Hangzhou, China 


\title{
Bringing Optics to Fab Labs in Europe
}

\author{
Aurèle Adam*a, Thim Zuidwijk ${ }^{\mathrm{a}}$ and Paul Urbach ${ }^{\mathrm{a}}$ \\ aptics Research Group, Delft University of Technology, Lorentzweg 1, 2628CJ Delft, The
} Netherlands

\begin{abstract}
The Optics Group of Delft University of Technology plays a major role in teaching optics to bachelor and master students. In addition, the group has a long record of introducing, demonstrating and teaching optics to quite diverse groups of people from outside of the university. We will describe some of these activities and focus on a recently started project funded by the European Commission called Phablabs 4.0, which aims to bring photonics to European Fab labs.
\end{abstract}

Keywords: Fab Labs, photonic toolkit, creativity, digital manufacturing.

\section{INTRODUCTION}

The time has past when researchers could sit in their ivory towers. Society at large and funding agencies in particular demand from academic scientists that they spend time on outreach and communication of their research results to the general public. Though some scientists may feel outreach as merely an obligation, others enjoy it. The Optics Group of Delft University of Technology, which celebrates its 70th anniversary this year, has a long tradition not only in academic research and education but also in providing service and advise to society in general and industry in particular. reason is Many of the members of the group enjoy doing these activities. During the past years the group has been active in several projects to disseminate research results on national and international exhibitions, to educate and train people from industry, in particular SME's, and to popularize and promote optics for the general public. Some of these activities have been done in the framework of projects funded by the European Commision as part of consortia consisting of many partners from all over Europe. We shall discuss some of the projects with an educational emphasis, namely the European projects $S M E T H O D S$, where several European academic groups gave trainings in optical design to people from industry, Photonics4all, which was started on the occasion of the Year of Light and aimed at the general public and companies, and some other educational activities.

In 2005 the first Fab Lab was started at MIT. The aim of Fab Labs is to provide access to the general public to computer enabled manufacturing. Fab labs have been started in many places all over the world, but usually optics and photonics tools are missing in Fab Labs. It is the aim of Phablabs 4.0 to bring optics and photonics to the Fab Lab community. We will explain in this paper in more detail how the consortium behind this project is trying to realize this.

*A.J.L.Adam@tudelft.nl; phone +31 1527 82455; http://www.optics.tudelft.nl/ 


\section{SMETHODS: HANDS-ON TRAININGS IN OPTICAL DESIGN}

SMETHODS stands for SME's Trainings and Hands-on in Optical Design of Systems. The motivation for starting this project was that in European industry there are insufficient people skilled in optical design. In most physics and related master programs, optical design is hardly taught. The bigger companies sometimes provide trainings in optical design for their employees but for small and medium sized enterprises (SME's), it is more difficult to get access to trainings. There are of course trainings given by companies that make software tools, but these are focused on learning how to work with a particular tool and much less on general principles and strategies of optical design. Therefore, a consortium of academic groups from the seven universities shown in Fig. 1 in seven different European countries from Spain to Russia, have carried out a so-called Support Action funded by the EU to provide trainings on these principles and strategies. Over a period of three years 16 trainings were given in four domains, namely:

- Imaging Optics

- Non-imaging Optics

- Wave Optics

- Diffractive Optics.

Thanks to the funding by the EU, the trainings were free for employees of SME's. As expected, Imaging Optics was the most popular domain with Non-Imaging Optics a good second. A training session typically took four days. During the first two days, the emphasis was on basic theory with examples while during the second half of the session hands-on training was given. The participants evaluated the sessions and made suggestions for improvements. At the end of the project the EU declared that SMETHODS was an "excellent project". The trainings in the Imaging Optics domain is since then continued as a self-financing activity under the name of SMETHODS+ in a collaboration between TU Delft, Institut d'Optique in Paris and TNO, an institute for applied scientific research in the Netherlands. In the future, a link will be made with the Dutch Optics Centre (DOC) which has been started in Delft in 2016 by Delft University of Technology and TNO. DOC is an ecosystem comprising academy, applied science institutes and companies which fosters research, development and education in optics and photonics.

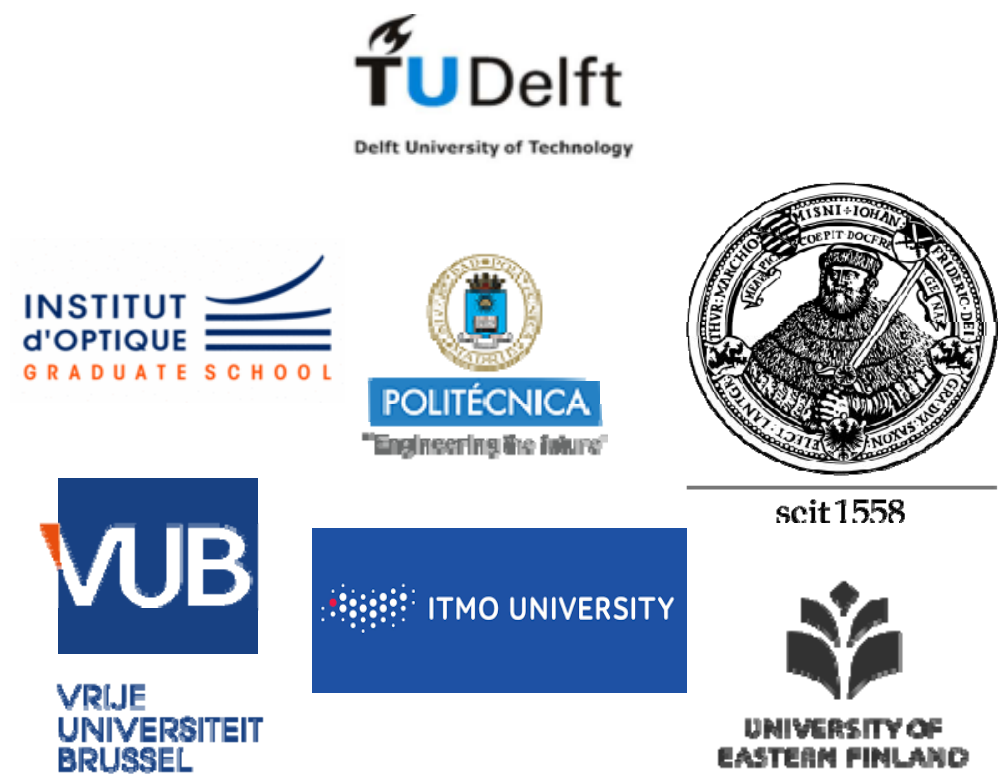

Figure 1. The consortium of the EU project SMETHODS on training and hands-on in optical design. The Optics Group of TU Delft was coordinator. 


\section{PHOTONICS4ALL}

Photonics4All was a project funded by the EU on the occasion of the Year of Light. It had a strong focus on education aiming in particular at high school students. The consortium consisted of nine partners in as many different European countries and was led by Stenbeiss Europa-Zentrum in Baden Wuertenberg in the south of Germany (Fig. 2 and http://photonics4all.eu). The Optics Group of TU Delft represented the Netherlands. Many activities were organised such as a photonics app (http://photonics4all-app.eu), photonics games, a children's video on youtube, a so-called Omnilight Laboratory, an online quiz and a Photonics Explorer Kit was developed to promote photonics to children. More than 900 high school teachers were trained in using the kits and it is estimated that more than 120.000 children were reached.

\section{OTHER REACHOUT}

Every year in December shortly before Christmas, there is an evening market in Delft were everybody can have a booth to sell homemade snacks and other items. Since many years the Optics Group also has a booth. Although one gets rather cold standing outside for a couple of hours, there is a reward in that many parents with young children visit the group who are fascinating by the optical effects that are demonstrated (Fig. 3).

The Optics Group also sustains a permanent exhibition about optics research in the Science Centre of Delft University of Technology. In October this year during the so called "Days of Science" a special holography exhibition will be organized. Last but not least the Optics Group is always present at the annual conference of high school teachers, where group members demonstrate educational kits (Fig. 4).

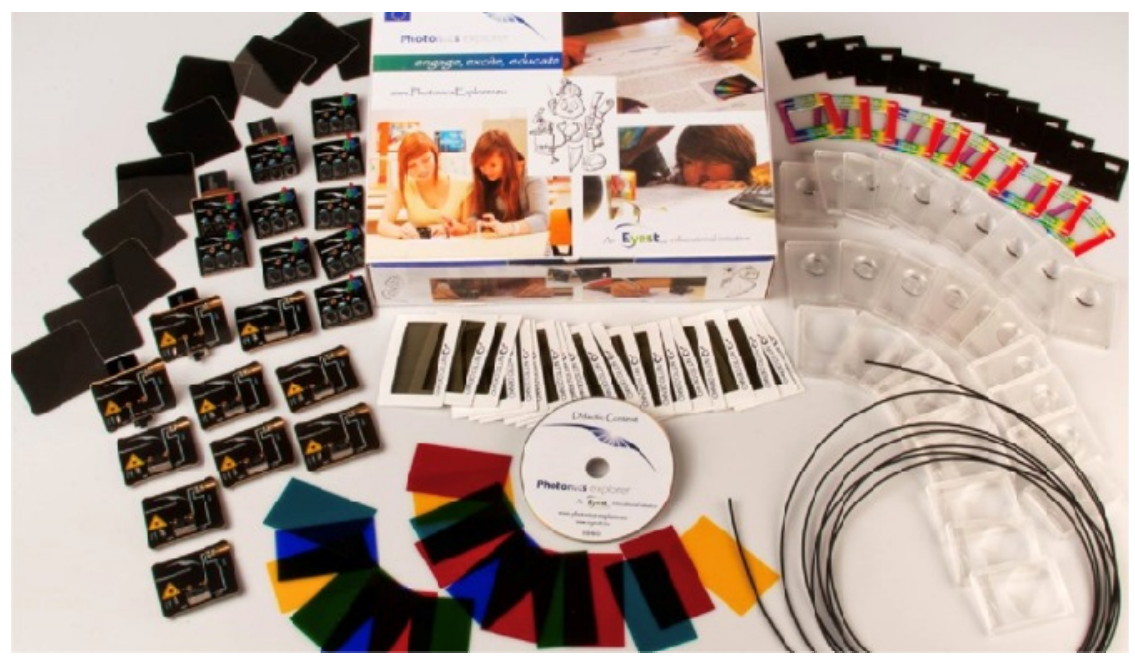

Figure 2. Photonics Explorer Kit has been developed by an international team of teachers and experts in pedagogy from 11 EU countries to fit into diverse educational systems, as part of an FP7 European project. It was disseminated to more than 900 high schools throughout Europe. 


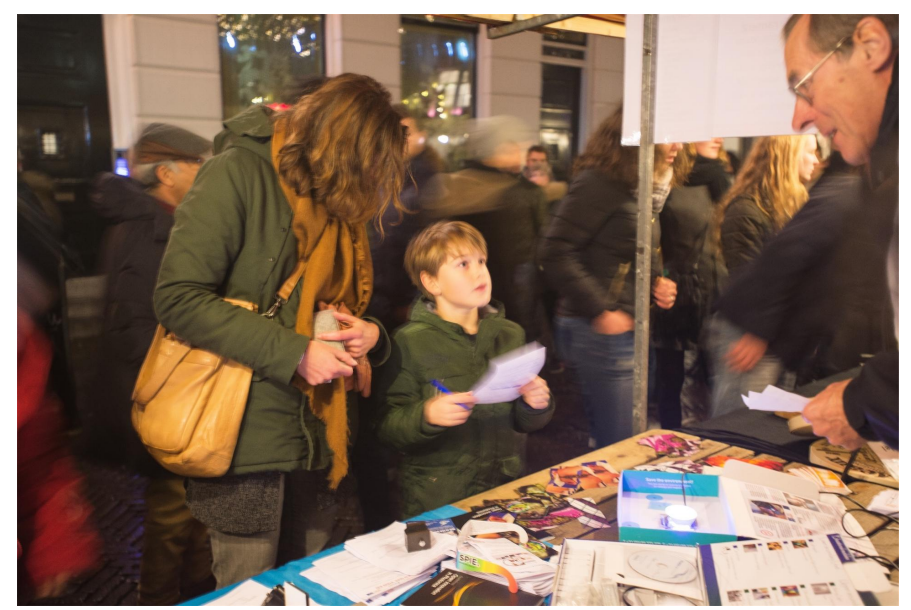

Figure 3. Optics booth at the public market shortly before Christmas in Delft.

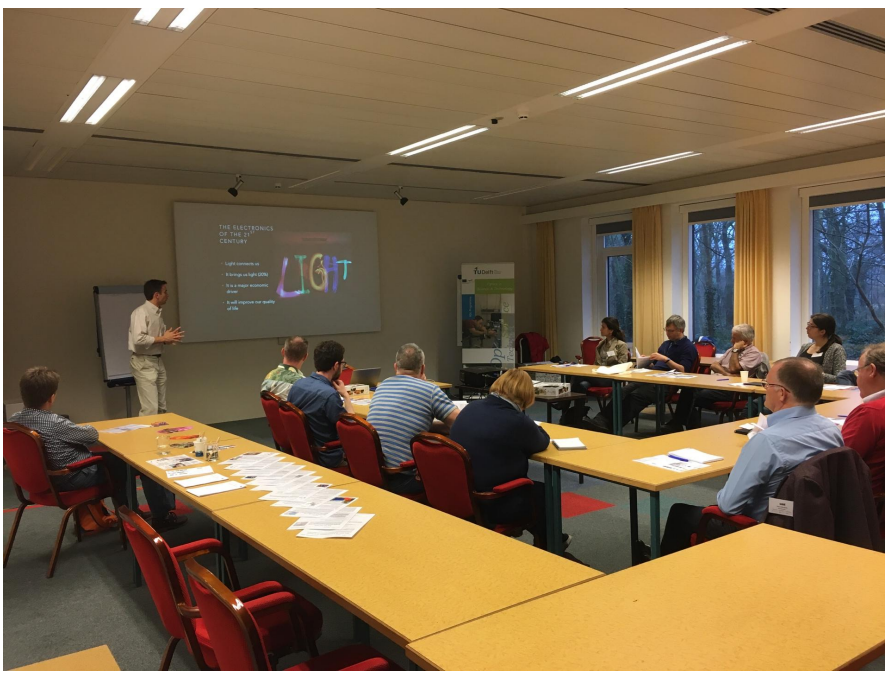

Figure 4. Demonstrating optical kits to high school teachers.

\section{PHABLABS 4.0}

\subsection{Fabrication Laboratories}

A Fabrication Laboratory (Fab Lab) is a small non-commercial workshop which gives open access to the general public for fabrication ${ }^{1,2}$. It is a platform for prototyping, learning and innovation and for stimulating entrepreneurship. As such it plays a major role in stimulating 21 th century skills ${ }^{3,4,5}$. In 2005 the first Fab Lab was started at MIT's Center for Bits and Atoms (CAB) of Prof. Neil Gershenfeld as an outreach activities of their research. The philosophy of this center is that the physical sciences, engineering and computer science will more and more converge and ultimately become one. The fabrication inside a Fab Lab is mainly by digitally controlled machines such as 3D printers, laser cutters, precision milling machines, vinyl cutters etc. A Fab Lab must have a basic set of machines to be called a Fab Lab. This list can be found on the website of the Fab Lab community: www.fabfoundation.org/fab-labs. The costs for equipment to start a 
Fab Lab are between $\$ 50,000$ and $\$ 100,000$. Additional costs are for renting appropriate space and for technical supervisors. Funding can have quite diverse origins. In Europe funding is often provided by local municipalities.

The number of Fab Labs is increasing very fast and there are now more than 1100 worldwide with around 80 in the U.S., 32 in The Netherlands and 11 in China.

Fab labs are important to increase interest among young students for science and technology ${ }^{6,7}$
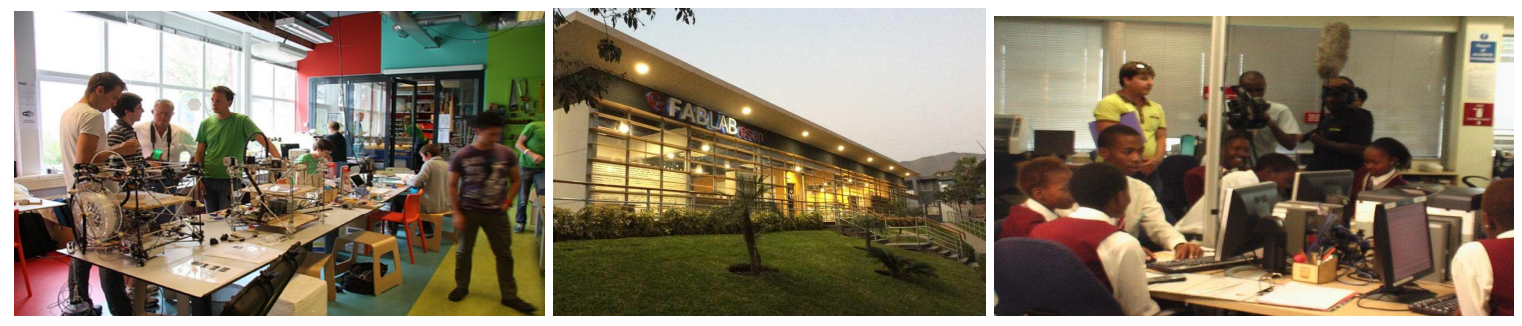

Figure 5. Fab Labs in Long Island (New York), Lima (Peru) and in South Africa (from left to right).

\subsection{Phablabs 4.0}

In general equipment with which optical instruments or instruments containing optical components can be made are lacking in Fab Labs. The project Phablabs 4.0 aims to bring photonics to Fab Labs. As SMETHODS, it is a Support Action funded by the EU. It has started in 2016 and will run for 3 years. There are thirteen partners form all over Europe with the Free University of Brussels as coordinator. Although existing Fab Labs are not partners in the consortium because they can not receive EU funding, a number of Fab labs are in the Advisory Board of the project. Furthermore, a group of pilot Fab labs tests the developed projects and toolkits and give feedback to improve them.

The number "4.0" in the name Phablabs 4.0 refers to the fourth industrial revolution which is now taking place. The first industrial revolution was due to steam engines, the second used electric power, the third was based on electronics and information technology. The fourth industrial revolution is characterized by a fusion of technologies, in particular physical, digital and biological technology.

The Phablabs 4.0 project has four objectives:

1. To develop and test photonics workshops for Fab Labs on 11 topics and tailored to 3 different target groups, namely a) young minds (age 10-14) b) students (age 15-18) c) young professionals and technicians (age 18+).

2. To develop and test 11 photonics challenger projects for the Fab labs as an eye-opener to the potential applications of photonics an to trigger the creativity and innovative strength of young professionals.

3. To compose and make available low-cost toolkits for photonics-enhanced Fab labs to stimulate and inspire innovation with photonics technology and components.

4. To scale-up and roll-out the photonics workshops, photonics challenger projects and the toolkits developed by Phablabs 4.0 to the European Fab labs.

\subsection{Photonics Workshops}

Photonics workshops are characterized by creative learning to acquire basic knowledge of photonics principles while working towards a functioning system in a short period of time. The 11 topics are listen in Table 1.

As an example, we consider the "Phonics meets textile workshop". The participants start studying the principle of total internal reflection and learn to use it to guide light from one place to another with fibers. These fibers can be integrated into textile to illuminate particular parts or design smart textiles. The expected outcome of this workshop for the three different target groups is listed in Table 2. 
Table 1 The eleven photonics workshops

1. Photonics meets textiles e.g. waveguides in cloths.

2. Photonics meets life e.g. portable optics for health monotoring.

3. Polarization e.g. in liquid crystal displays.

4. Driving light around e.g. using waveguides.

5. Optical sensors for robot.

6. Illumination optics for art.

7. Lasers and holograms.

8. Photonics in lighting using LEDs.

9. Photonics meets new structure: e.g. accurate positioning technology.

10. Lenses for optical images, e.g. 3D printing of Fresnel lenses.

11. Laser meets digital fabric printing.

Table 2 Outcome of Workshop "Photonics meets textile workshop" depending on age group.

\begin{tabular}{|c|c|c|c|}
\hline Level & Outcome of the "Photonics workshops" & $\begin{array}{l}\text { Tools used } \\
\text { of the fab } \\
\text { labs }\end{array}$ & $\begin{array}{l}\text { Photonics } \\
\text { Components }\end{array}$ \\
\hline Basic & $\begin{array}{l}\text { The participants will enhance their cuddly toy like a dinosaur } \\
\text { or a different object with light, using one light source and a } \\
\text { bundle of plastic optical fibers to guide the light to several } \\
\text { places on the object for illumination purposes. }\end{array}$ & $\begin{array}{l}\text { sewing } \\
\text { machine }\end{array}$ & $\begin{array}{l}\text { plastic optical } \\
\text { fibers, LED }\end{array}$ \\
\hline Middle & $\begin{array}{l}\text { The participants will build lighting aspects into a glove. They } \\
\text { will learn how to integrate small LEDs and lasers, a mini } \\
\text { controller and a battery into a bracelet attached to the glove. } \\
\text { The light from the LEDs will be guided by small optical fibers } \\
\text { towards several parts in the glove. }\end{array}$ & $\begin{array}{l}\text { sewing } \\
\text { machine }\end{array}$ & $\begin{array}{l}\text { optical fibers } \\
\text { lens, LEDs, } \\
\text { lasers }\end{array}$ \\
\hline Advanced & $\begin{array}{l}\text { The participants will make a smart backpack for a cyclist which } \\
\text { indicates with light which direction they will turn, thus } \\
\text { improving the safety for the cyclist. Therefore they will apply } \\
\text { the same principles learned in the previous level but now also } \\
\text { learn how to form controllable images with the fibres and } \\
\text { controlled light sources. }\end{array}$ & $\begin{array}{l}\text { sewing } \\
\text { machine }\end{array}$ & $\begin{array}{l}\text { optical fibers } \\
\text { LEDs }\end{array}$ \\
\hline
\end{tabular}




\subsection{Photonics Challenger Projects}

These projects are longer term than the photonics workshops. The emphasis of the practical assignments is on stimulating creativity. The practical challenge must be solved with photonics tools and components. The role of the instructor is that of a coach. Participants will be given access to all necessary tools. The eleven challenger projects are described in Table 3.

Table 3 Challenger Projects

1. Light as information carrier (VUB): explore wireless communication with visible light.

2. Photonic plant monitoring (ICFO).

3. Optical proximity sensors to make music with you fingers (FBH).

4. Photonics for fashion and design (IFN-CNR): light integrated with cloths.

5. Make your own 3D scanner (NUI).

6. Design and make hidden images without display (UJM-IOGS): e.g. using reflection, polarisation.

7. Art and design with holography (UOS).

8. LED as a new illumination source (JR): build your own sophisticated LED lamp.

9. Collecting solar energy (SEZ): e.g. make a solar oven to boil water.

10. LEDs and light sheets for Plants (TUD), get the proper wavelengths to the proper plants with the appropriate light intensity.

11. Light as an object detector (FTMC), e.g. think of ways to detect hidden objects (aroud the corner) with laser light.

Typically, every partner of the Phablabs 4.0 consortium develops one project. As an example we describe challenger project 4 "Photonics for fashion and design" in Figure 6.

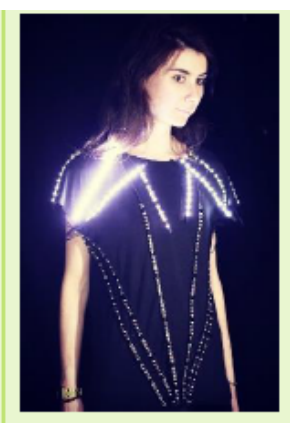

Photonics for fashion and design - Photonics, together with Fab Labs equipment and participants' creativity, can be used to make fashion and design objects which are more interactive, charming and cool. The use of light and its interaction with materials and objects allows one to create photonics-enhanced clothes and other lifestyle accessories and objects. This can be realized with LEDs, (woven) optical fibers, LilyPad Arduino (or similar controllers), various optical elements etc. Possible applications range from safety (workers, cyclists etc.), wearable emoticons using a "mood by colour" approach, new lightbased accessories, wearable art, or games design. This is an interesting and broad challenge that can be particularly appreciated by young professionals and entrepreneurs, and that can help in tackling the STEM gender gap.

Figure 6. description of the Photonics Challenger Project "Photonics for fashion and design".

At the midpoint of project Phablabs 4.0 a "Photonics challenger project contest" will be launched. Three awards will be handed out at the end of the project, namely for 1 . the most innovative photonics project; 2 . the photonics project with highest societal impact; 3 . the most innovative photonics component realized with 3D manufacturing. 


\subsection{Time plan}

The photonics workshops for the 11 topics and 3 age groups are tested and evaluated by 14 local pilot Fab Labs. The same applies to the Photonics Challenger Projects and the toolkits. Based on the received feedback, the workshops, challenger projects and toolkits will be improved.

At the end of the project the pilot Fab Labs will select the most suitable workshops, challenger photonics projects and toolkits. One of the partners of Phablabs 4.0, the Belgium organization EYESTvwz which aims at increase interest of youth in engineering, science and technology, will distribute these further to other Fab Labs and will also guarantee continuation after the end of the project.

\section{CONCLUSION}

Academic scientist can and should play a major role in educating not only students of their institution but also people from outside of the university. Although for some scientists outreach is a mere obligation, for many it is a very satisfactory task. We have given several examples of effective outreach to the general public. The booming Fab Labs, which also have started as an outreach activity, have now spread all over the world. The Fab Labs enables access for the general public to computer steered manufacturing such as 3D printing. However, photonics components were usually lacking and therefore photonic component could not be integrated in manufactured systems and devices. In the project Phalabs 4.0 which is funded by the EU, thirteen partners aim at bringing photonics to the Fab Labs by making suitable toolkits and developing workshops and challenger topics. This will not only broaden the scope of the Fab labs, but will also help to promote photonics and advertise its huge potential for applications for the general public.

\section{REFERENCES}

[1] Mikhak, B. Lyon, C., Gorton T., Gershenfeld, N. McEnnis. C. and Talor J.., "Fab Lab: an alternate model of ICT for development", http://18.85.8.56/events/03.05.fablab/fablab-dyd02.pdf

[2] Posch, I., Ogawa, H., Lindinger C., Haring R., Hoernter, H. "Introducing the FabLab as interactive exhibition space", Proc. IDC'10, Proceeding of the 9th International Confrence on Interaction Design and Children, Pages 254-257 (2010).

[3] Bernie Trilling \& Charles Fadel, 21st [Century Skills, learning for life in our times], Wiley (2012).

[4] https://www.weforum.org/agenda/2016/03/21st-century-skills-future-jobs-students.

[5] Ananiadou, K. and M. Claro (2009), "21st Century Skills and Competences for New Millennium Learners in OECD Countries”, OECD Education Working Papers, No. 41, OECD Publishing. http://dx.doi.org/10.1787/218525261154.

[6] Sagebiel, F., Alemany, C., Dahmen, J., Davidsson, B., Godfroy-Genin, A.-S., Kolvekova, G., Pinault, C. Rommes, E., Schönberger, M., Thaler, A., Urbancíková, N., Wächter, C., "Promoting positive images of SET in young people under gender perspective". MOTIVATION project: final report. (2010)

[7] Hong, Z. R., Lin, H. S. "An Investigation of Students? Personality Traits and Attitudes toward Science", International, journal of Science Education, 33(7), 1001-1028 (2011). 